\title{
Ranking risks in ambient intelligence projects
}

\author{
C. López ${ }^{* 1}$, J.L. Salmeron ${ }^{2}$ \\ 1,2 Universidad Pablo de Olavide, \\ Ctra. de Utrera, km. 1, 41013, Sevilla, España \\ *clopvar@upo.es
}

\begin{abstract}
At present, numerous ambient intelligent $(\mathrm{Aml})$ applications are emerging which support current electronic and digital environments. Professionals develop each of them by means of projects. Aml application projects have certain features that make them different from other engineering projects. Moreover, a wide rage of risks are present in the whole project. Therefore, to increase these projects' chances to be successful, it is necessary to manage their specific risks adequately. In order to support the work of those practitioners managing these threats, this research proposes a multicriteria decision-making methodology called Analytic Hierarchy Process. This technique will enable the prioritization of risks in Aml projects according to their level of threat.
\end{abstract}

Keywords: Aml applications, risk management, multicriteria decision-making methodology, software development.

\section{RESUMEN}

Hoy en día se están desarrollando numerosos sistemas de inteligencia ambiental (Aml) que soportan los actuales entornos electrónicos y digitales. Los profesionales desarrollan estas aplicaciones por medio de proyectos, los cuales tienen ciertas características que los diferencian de otros proyectos de ingeniería; además, una gran variedad de riesgos están presentes, amenazando su ejecución y resultado final. Por lo tanto, para aumentar la probabilidad de que estos proyectos culminen exitosamente, es necesario gestionar adecuadamente los riesgos que los amenazan. Con el fin de facilitar a los profesionales la labor de gestión de estos riesgos, esta investigación propone la aplicación de una metodología de decisión multicriterio, denominada AHP. Esta técnica nos permitirá priorizar los riesgos existentes en los proyectos de Aml de acuerdo con su nivel de amenaza.

\section{Introduction}

Ambient intelligence (Aml) is changing the traditional view of Information Technologies (IT). In fact, the vision of Aml is being extended to such diverse fields such as smart homes [1], transportation [2], education [3], healthcare [4], and other areas [5].

This discipline promotes the integration of IT into a digital environment, which adapts and responds to people needs, desires, habits, gestures and emotions. This environment can be seen as a huge distributed network consisting of thousands of interconnected embedded systems that surround the user and meet his/her information, communication and entertainment needs, simplifying and automating his/her professional and personal activities.

Aml systems must be sensitive, responsive, adaptive, transparent, ubiquitous, and intelligent [6].
Hence, basic technological requirements [7], which evolve very quickly, are required for their development. The teams that develop Aml systems have to use immature technologies and tools; furthermore, Aml development projects are regarded as great size and complex projects; hence many risks can threaten them [8,9]. In fact, a large percentage of Aml projects are not completed on time or do not meet the established requirements. To avoid this, practitioners have to properly manage the existing risks in their Aml projects.

Risk management is a systematic approach to minimize the impacts of existing risks, making the AmI projects less vulnerable and the systems more robust. Recently, numerous disciplines have arisen to guide practitioners in the management of risks in software projects. The most extended one has been the proposed by the SEl (Software 
Engineering Institute) [10]. The SEI risk management paradigm states that the risks have to be continuously identified and analyzed throughout the life cycle of the project.

Aml project teams can detect many different kinds of risks. To help them, we identified and analyzed the risks in Aml projects; to do so, we used a multicriteria decision-making methodology called Analytic Hierarchy Process (AHP). The results indicate where the Aml project teams must focus on treating and mitigating the risks.

The rest of the paper is organized into five sections. Section 2 provides a brief presentation of AHP fundamentals. Following this, Section 3 introduces the research model. Section 4 reports the main results obtained from the study. Finally, Section 5 presents some conclusions.

\section{AHP Methodology}

The AHP methodology was developed by Saaty $[11,12]$ in the $70 \mathrm{~s}$. It is a powerful and flexible decision-making process to set priorities among different attributes. AHP is a method that uses a hierarchic structure to present a complex-decision problem by decomposing it into several smaller subproblems. This has been widely used to reflect the importance, or weights, of the factors associated with priorities [13]. The AHP method represents problems through the identification of goals, criteria, and sub-criteria.

AHP allows respondents to express their individual preferences. Therefore, each element at the hierarchy can be evaluated using this set of preferences, thus providing a ranking specific for each decision-maker involved. The AHP methodology application permits the prioritization of the criteria of the hierarchical model. To attain this, the hierarchical elements are evaluated and compared binarily by assigning weights.

The AHP method encompasses three basic stages (see Figure 1). Firstly, the decision problem has to be broken down into a hierarchy of interrelated elements. Secondly, the data has to be collected by pairwise comparisons of former elements and the attributes' weights in each level have to be computed using the eigenvalue method. Finally, the categories' weights have to be calculated and the final ranking obtained.

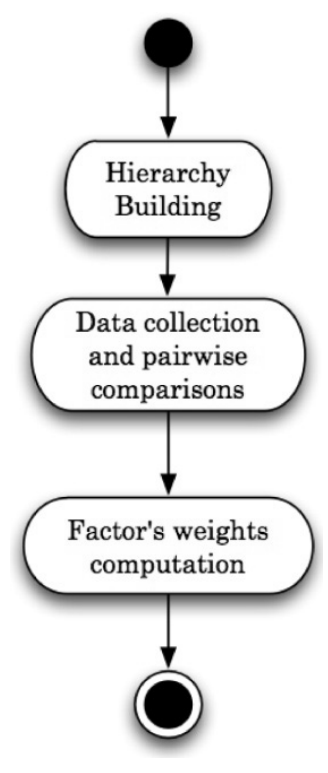

Figure 1. AHP stages

The choice of this tool is due to its multiple advantages. In the beginning, this allows breaking down and analyzing risks in parts. In practice, the tool is supported by mathematical concepts which permits the participation of different experts and creates a consensus.

\section{Research model}

This research was aimed at analyzing risk factors in the development of Aml applications projects. In this way, five experts in the development of Aml applications actively participated in this study. The optimal number of experts depends on the characteristics of the study itself. We can, however, say that the greater the heterogeneity of the group, the fewer the number of experts recommended, 5 being a good size [14, 15]. A heterogeneous group is understood to be a group of people with the same knowledge but on a different social or professional scale - which is what took place in our study. Table 1 shows the profile of consulted experts.

The experts were not chosen just because they were easily accessible. Multiple choices were explored to select them. The main selection criterion was profound knowledge and experience in Aml projects and absence of conflicts of interest. 


\begin{tabular}{|c|c|}
\hline \multicolumn{2}{|l|}{ Positions } \\
\hline Project leader & $40 \%$ \\
\hline Analyst & $60 \%$ \\
\hline \multicolumn{2}{|c|}{ Academic background } \\
\hline Ph.D. & $20 \%$ \\
\hline MSc. & $60 \%$ \\
\hline MBA & $20 \%$ \\
\hline \multicolumn{2}{|c|}{ Average experience in Aml projects } \\
\hline $1-5$ years & $40 \%$ \\
\hline $5-9$ years & $40 \%$ \\
\hline 10 years and over & $20 \%$ \\
\hline
\end{tabular}

Table 1. Experts' profile.

\begin{tabular}{|c|c|c|}
\hline Categories & ID & Risks \\
\hline \multirow{6}{*}{$\begin{array}{l}\text { Requirement } \\
\text { Risks }\end{array}$} & R.1 & Aml requirements are not clearly defined \\
\hline & R.2 & $\begin{array}{l}\text { Continual stream of changes of } \mathrm{Aml} \\
\text { requirements }\end{array}$ \\
\hline & R.3 & Excessively complex Aml requirements \\
\hline & R.4 & Gold plating \\
\hline & R.5 & Evaluation of performance of Aml requirements \\
\hline & R.6 & Failure to manage end-user expectations \\
\hline \multirow[t]{4}{*}{$\begin{array}{l}\text { Management } \\
\text { Risks }\end{array}$} & M.1 & $\begin{array}{l}\text { Cannot locate or effectively manage external } \\
\text { software development }\end{array}$ \\
\hline & M.2 & Unrealistic schedules and budgets \\
\hline & M.3 & Plan of the Aml project is short of details \\
\hline & M.4 & Cannot meet milestones of Aml project \\
\hline \multirow{6}{*}{$\begin{array}{l}\text { Technical } \\
\text { Risks }\end{array}$} & T.1 & Developing the wrong Aml application functions \\
\hline & T.2 & Developing the wrong users' interfaces \\
\hline & T.3 & Immaturity of the new technology \\
\hline & T.4 & Incompatible artefacts \\
\hline & T.5 & Inadequate simulation tools \\
\hline & T.6 & $\begin{array}{l}\text { Inadequate estimation of hardware and } \\
\text { software capabilities }\end{array}$ \\
\hline \multirow{4}{*}{$\begin{array}{l}\text { Human } \\
\text { Resources } \\
\text { Risks }\end{array}$} & P.1 & Insufficient human resources \\
\hline & P.2 & Team members lack required knowledge/skills \\
\hline & P.3 & Team members lack proper training \\
\hline & P.4 & High turnover within project team \\
\hline
\end{tabular}

Table 2. Taxonomy of risks. 
The experts selected started identifying the risk factors. The result was a list made up of 20 risks. We grouped the risks in categories according to their shared features. Subsequently, the experts checked the classification of risks or preliminary hierarchy. Afterwards, the hierarchy of risks was completed to perform the corrections indicated by the experts and for the classification to be accepted by all them.

Table 2 presents the elements of the hierarchy of risks. Subsequently, experts compared pairs of elements within the final hierarchy. Finally, the factors' weights were computed. The result allowed prioritizing the risks according to their importance.

\subsection{Constructing the hierarchy}

The determination of the degree of importance associated with the risk factor can be resolved by decomposing it into sub-problems within a hierarchy structure. Elements in the middle levels are the categories for evaluating the risk factors. Four categories for classifying risks according to their characteristics were established: requirements, management, technical and human resources. The third level shows the specific risks within each category. Figure 2 shows the hierarchy obtained.

\subsection{Pairwise comparison}

In this phase, the risk factors are compared in terms of their importance within a given category. That is, the risks of all categories have to be compared (within their own category). The widely accepted nine-point scale which is the original scale suggested by Saaty [12] was used. Table 3 presents the scale used.

The numerical values representing the judgements of the pairwise comparisons are arranged in the upper triangle of the square matrix. For example, it represents how much criteria $i$ is preferred over criteria $j$. This means that

$$
a_{i j}=w_{i} / w_{j}
$$

The elements in the main diagonal of $A$ are all equal to 1 and the elements of the lower triangle are the inverse of the elements in the upper triangle, i.e., $\quad a_{j i}=1 / a_{i j}=1 /\left(w_{i} / w_{j}\right)=w_{j} / w_{i}$. Each of its elements $a_{i j}$ is the ratio of the absolute weight with respect to the importance of criteria $i$ over the absolute weight with respect to the importance of criteria $j$. Note that the matrix is provided directly by the results of the questionnaire. Therefore, the matrix is as follows:

$$
\begin{aligned}
A & =\left(a_{i j}\right),(i, j=1, \ldots, n) \\
A & =\left(\begin{array}{ccc}
1 & \ldots & a_{i j} \\
\ldots & 1 & \ldots \\
a_{j i} & \ldots & 1
\end{array}\right)
\end{aligned}
$$

That is

$$
A=\left(\begin{array}{cccc}
1 & \ldots & w_{i} / w_{j} & \ldots \\
\ldots & 1 & \ldots & \ldots \\
w_{j} / w_{i} & \ldots & 1 & \ldots
\end{array}\right)
$$

\subsection{Computation of the weights of the factors}

We are interested in knowing the value of the weight of each attribute in itself (the vector of priorities), not the weights when compared to the other attributes. This is done in this step. Note also that this matrix verifies that

$$
A \cdot w=n \cdot w
$$

where $w$ is the vector of the actual absolute weights and $n$ is the number of criteria.

These weights must verify [11]:

$$
A \cdot w=\lambda_{\max } \cdot w
$$

where $\lambda_{\max }$ is the largest eigenvalue of $A$ and $w$ is the eigenvector associated with that eigenvalue. 


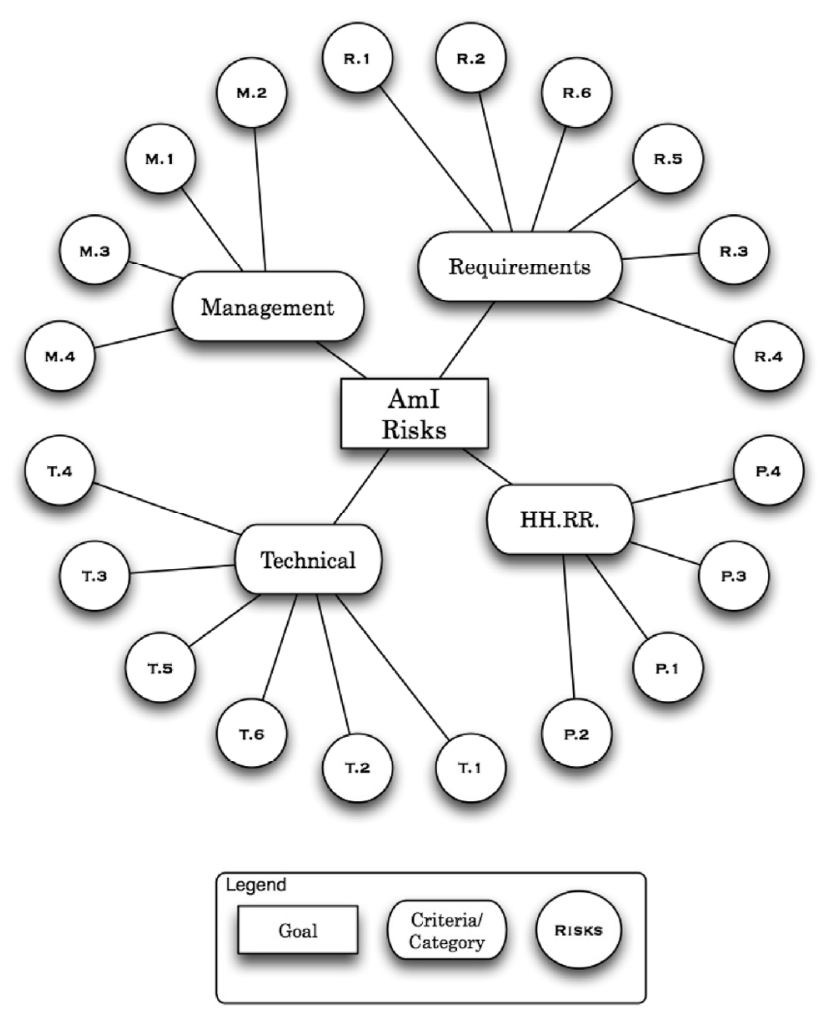

Figure 2. Hierarchy of risks.

\begin{tabular}{|l|l|}
\hline $\begin{array}{l}\text { Numerical } \\
\text { rating }\end{array}$ & Verbal judgements of preferences \\
\hline 1 & A is equally critical to B \\
\hline 2 & A is equally to moderately critical over B \\
\hline 3 & A is moderately critical over B \\
\hline 4 & A is moderately to strongly critical over B \\
\hline 5 & A is strongly critical over B \\
\hline 6 & A is strongly to very strongly critical B \\
\hline 7 & A is very strongly critical over B \\
\hline 8 & A is very strongly to extremely critical over B \\
\hline 9 & A is extremely critical over B \\
\hline
\end{tabular}

Table 3. Pairwise comparison scale. 
Finally, measuring the consistency of the judgements of the answers is required. The value $\lambda_{\text {max }}=n$ should always be the largest eigenvalue. However, inconsistencies in the respondents' answers may lead to a different value. The closer it is to $n$, the greater the consistency of the answer.

A normalized consistency ratio (CR), based on the divergence of the largest eigenvalue to $n$, is commonly used in the literature [12]. The maximum accepted upper value for the consistency ratio is 0.1 [13]. In this study, the consistency ratio was 0.07 . So the experts' answers were consistent.

\section{Findings}

The findings obtained by applying the AHP methodology are shown in Table 4. These provide the teams developing Aml applications with relevant information.
Firstly, Table 4 shows a ranking of global weightbased risk categories. This indicates which categories are most critical. The teams thus have a guide that shows where they should focus their strengths. Requirement Risks is the most critical category. Its global weight was 0.426 . This was about 1.4 to 5.8 times greater than Management Risks (0.073), Technical Risks (0.311), and Human Resources Risks (0.19).

Secondly, Table 4 summarizes the local weights of risks for each risk category. In other words, it shows the ranking of risks within each category. In the Requirement Risks Category (Figure 3), "excessively complex Aml requirements" was the most critical risk with a local weight of 0.375 . It was about 1.4 to 11.4 times greater than "Aml requirements are not clearly defined" (0.271), "continual stream of changes of Aml requirements" (0.158), "gold plating" (0.033), "evaluation of performance Aml requirements" (0.109), and "failure to manage end-user expectations" (0.053).

\begin{tabular}{|c|c|c|c|c|}
\hline Categories & ID & Local weight & $\begin{array}{l}\text { Global } \\
\text { Weight }\end{array}$ & Ranking \\
\hline \multirow{6}{*}{$\begin{array}{l}\text { Requirement Risks } \\
\text { Global weight: } \\
0.426 \\
\text { (1) }\end{array}$} & R.1 & $0.271(2)$ & 0.115 & $3^{\circ}$ \\
\hline & R.2 & $0.158(3)$ & 0.067 & $5^{\circ}$ \\
\hline & R.3 & $0.375(1)$ & 0.159 & $1^{\circ}$ \\
\hline & R.4 & $0.033(6)$ & 0.014 & $15^{\circ}$ \\
\hline & R.5 & $0.109(4)$ & 0.047 & $9^{\circ}$ \\
\hline & R.6 & $0.053(5)$ & 0.023 & $13^{\circ}$ \\
\hline \multirow{4}{*}{$\begin{array}{l}\text { Management Risks } \\
\text { Global weight: } \\
0.073 \\
(4)\end{array}$} & M.1 & $0.096(3)$ & 0.007 & $19^{\circ}$ \\
\hline & M.2 & $0.651(1)$ & 0.048 & $8^{\circ}$ \\
\hline & M.3 & $0.206(2)$ & 0.015 & $14^{\circ}$ \\
\hline & M.4 & $0.048(4)$ & 0.004 & $20^{\circ}$ \\
\hline \multirow{6}{*}{$\begin{array}{l}\text { Technical Risks } \\
\text { Global weight: } \\
0.311 \\
(2)\end{array}$} & $\mathrm{T} .1$ & $0.474(1)$ & 0.148 & $2^{\circ}$ \\
\hline & T.2 & $0.202(2)$ & 0.063 & $6^{\circ}$ \\
\hline & T.3 & $0.038(6)$ & 0.012 & $17^{\circ}$ \\
\hline & T.4 & $0.046(5)$ & 0.014 & $16^{\circ}$ \\
\hline & T.5 & $0.101(4)$ & 0.032 & $11^{\circ}$ \\
\hline & T.6 & $0.139(3)$ & 0.043 & $10^{a}$ \\
\hline \multirow{4}{*}{$\begin{array}{l}\text { Human Resources Risks } \\
\text { Global weight: } \\
0.19 \\
(3)\end{array}$} & P.1 & $0.065(4)$ & 0.012 & $18^{\circ}$ \\
\hline & P.2 & $0.502(1)$ & 0.095 & $4^{\circ}$ \\
\hline & P.3 & $0.306(2)$ & 0.058 & $7^{\circ}$ \\
\hline & P.4 & $0.127(3)$ & 0.024 & $12^{\circ}$ \\
\hline
\end{tabular}

Table 4. Categories and risks ranking with local and global weights. 


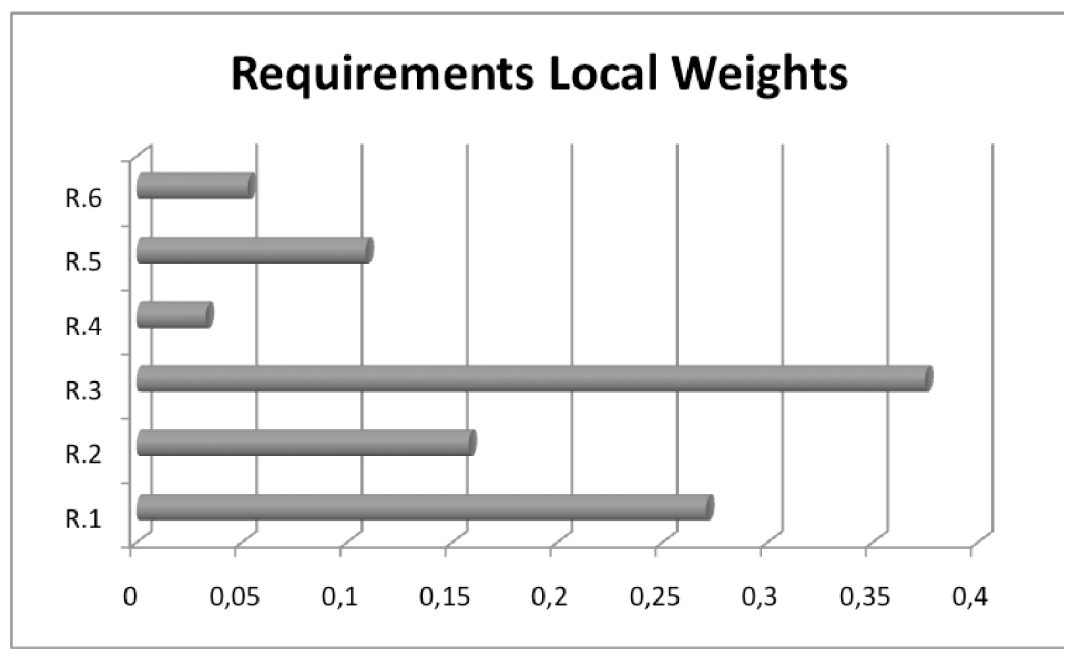

Figure 3. Requirements local weights.

The most critical risk with a local weight of 0.651 was "unrealistic schedules and budgets" in the Management Risks Category (Figure 4). This was about 3.2 to 13.6 times greater than "cannot locate or effectively manage external software development" (0.096), "plan of the Aml project is short of details" (0.206), and "cannot meet Aml project milestone" (0.048).
"Developing the wrong Aml application functions" got the highest value with a local weight of 0.474 in the Technical Risks Category (Figure 5). It was 2.3 to 12.5 times greater than "developing the wrong users interfaces" (0.202), "immaturity of the new technology" (0.038), "incompatible artefacts" (0.046), "inadequate simulation tools" (0.101), and "inadequate estimation of hardware and software capabilities" (0.139).

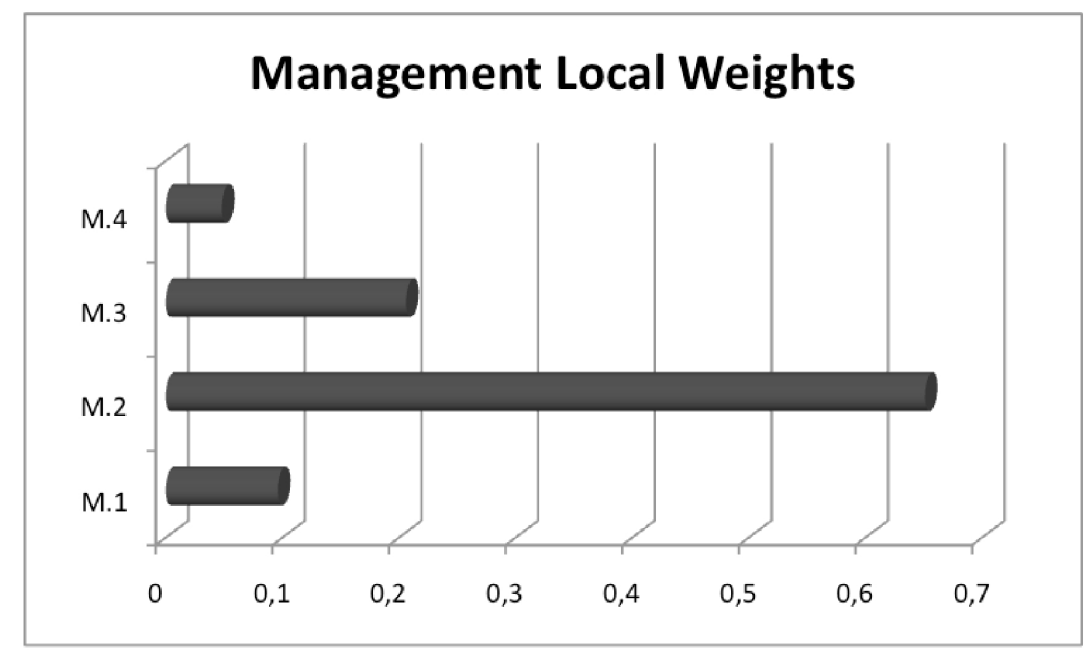

Figure 4. Management of local weights. 


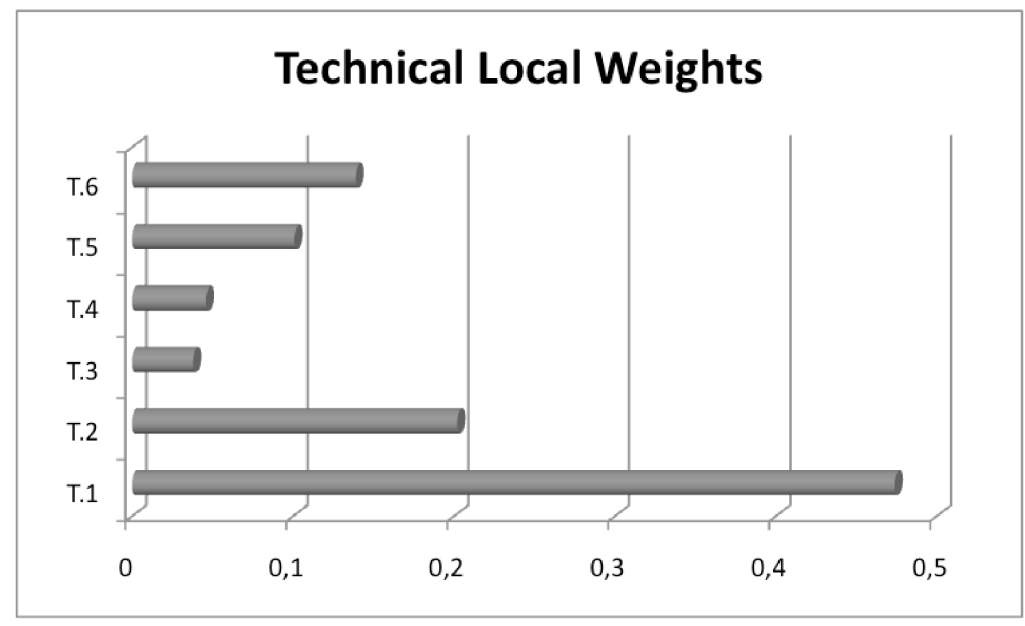

Figure 5. Technical local weights.

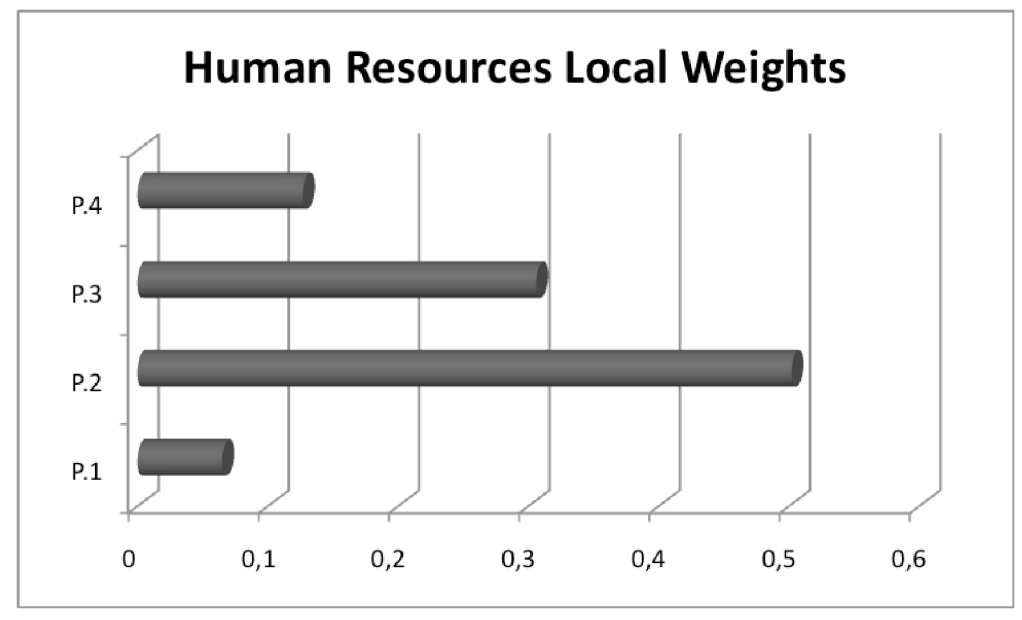

Figure 6. Human Resources local weights.

"Team members lack required knowledge/skills" was the most critical risk with a local weight of 0.502 in the Human Resources Risks Category (Figure 6). It was 1.6 to 7.7 times greater than "insufficient human resources" (0.065), "team members lack proper training" (0.306), and "high turnover within development team" (0.127).

Finally, Table 4 presents the ranking of global weights-based risks (Figure 7). In other words, the risks are ranked from highest to lowest in terms of causes of the failure. The ranking is based on global weights. They have been calculated by multiplying the local weights of each risk by the global weight of each category. By doing this, each local risk is balanced by the importance of the category to which it belongs.

"Excessively-complex Aml requirements" was the most critical factor with a global weight of 0.159 . This was from 1.1 to 40 times greater than the rest. The second risk was "developing the wrong Aml application functions" (0.148). The third was "Aml requirements are not clearly defined" $(0.115)$. The fourth was "team members lack required knowledge/skills" (0.095). The fifth was "continual stream of Aml requirement changes" (0.067). These five risks add up to $58.4 \%$ of the global total weight. 


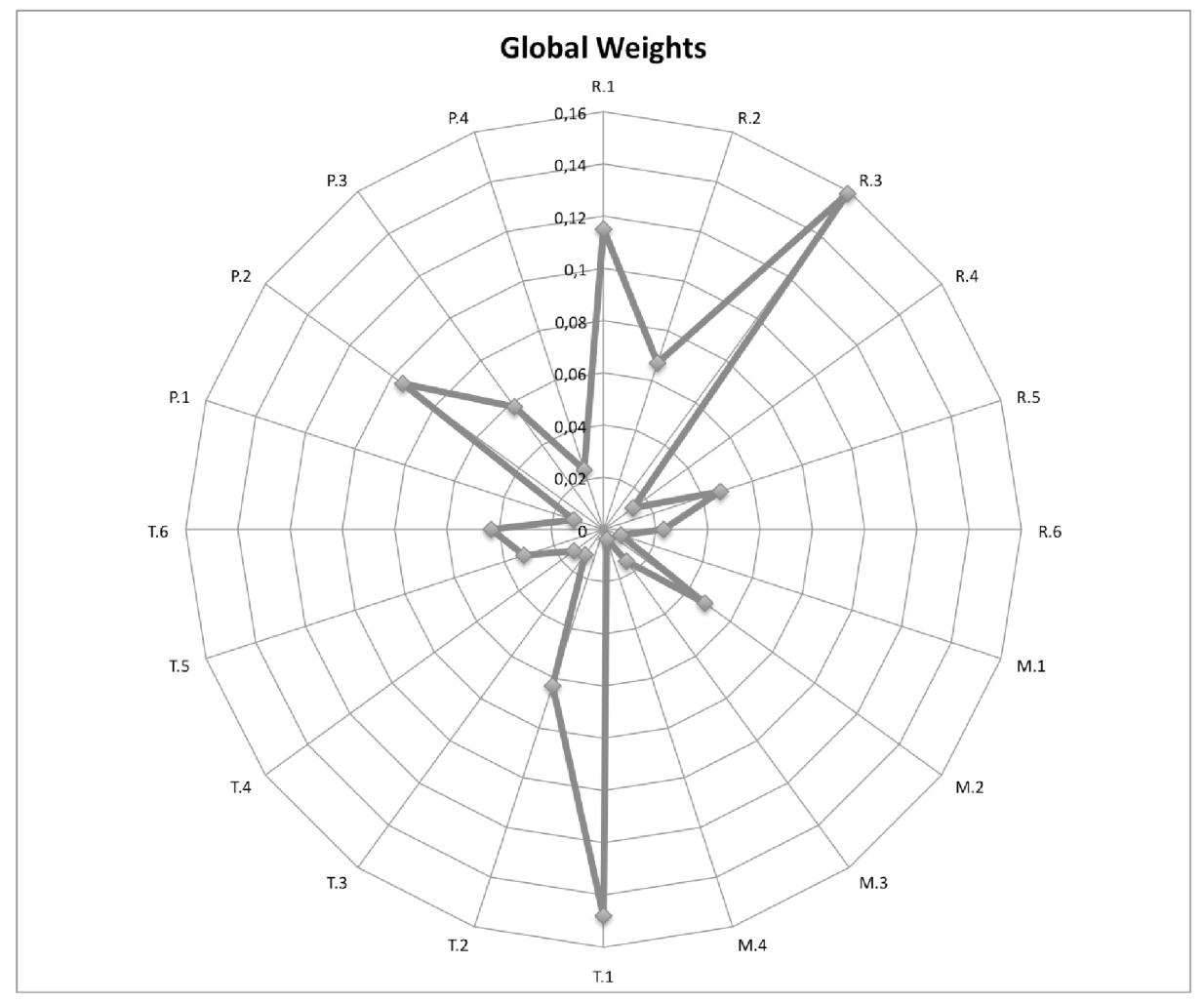

Figure 7. Global weights.

\section{Conclusions}

The aim of this research was to study the risk factors that threaten the performance of Aml projects. To do so, we have devised a classification of risks according to their shared features. This identifies the risks faced by development teams of Aml applications. In addition, we used a multicriteria decision-making tool to prioritize the risk factors identified. The results do not mean that any risk is unimportant. They indicate what the respondents' perceptions about the importance of them are.

For academics, the taxonomy provides grounding for further studies. Moreover, the results indicated risks that managers and practitioners must focus their attention and efforts on to control them. The risks derived from the requested requirements are the most serious. This category gathers 3 to 5 of the most critical risks.
Practitioners should thus identify, clearly define and control the flows of the Aml application requirements during their development. The second and fourth most important risks were, respectively, "developing the wrong Aml application functions" and "team members lack required knowledge/skills". Both risks are closely related. The application functions can be damaged by the scarce knowledge or skills of the team personnel, among other factors. Therefore, to achieve success in Aml development projects, managers should form teams of experienced professionals. 


\section{References}

[1] Helal A, Mann W., El-Zabadani H., King J., Kaddoura Y., Jansen E., The gator tech smart house: A programmable pervasive space, IEEE Computer, Vol. 38, No. 3, 2005, pp. 50-60.

[2] Rakotonirainy A., Tay R., In-vehicle ambient intelligent transport systems (i-vaits): Towards an integrated research, 7th International IEEE Conference on Intelligent Transportation Systems, 2004, pp. 648--651. Washington DC, EEUU.

[3] Shi Y., Xie W., Xu G., Shi R., Chen E., Mao Y., Liu F., The smart classroom: Merging technologies for seamless tele-education, IEEE Pervasive Computing, Vol. 2, No. 2, 2003, pp. 47-55.

[4] Isern D., Sánchez D., Moreno A., Agents applied in health care: A review, International Journal of Medical Informatics, Vol. 79, No. 3, 2010, pp. 145-166.

[5] Gadzheva M., Privacy in the Age of Transparency, Social Science Computer Review, Vol. 26, No. 1, 2008, pp. 60-74.

[6] Cooka D.J., Augusto J.C., Jakkula V.R., Ambient intelligence: Technologies, applications, and opportunities, Pervasive and Mobile Computing, Vol. 5, No. 4, 2009, pp. 277-298.

[7] Vrana I., Aly S., Conceptual models for managerial ambient intelligence, 2th International Ambient Intelligence Forum, 2009, pp. 53-63, Prague, Czech Republic.

[8] Augusto, J.C., McCullagh, P., Ambient Intelligence: Concepts and Applications, Computer Science and Information Systems, Vol. 4, No. 1, 2007, pp. 1-28.

[9] Raisinghani, M., Benoit, A., Ding, J., Gomez, M., Gupta, K., Gusila, V., Power, D., Schmedding, O., Ambient intelligence: Changing forms of humancomputer interaction and their social implications, Journal of digital information, Vol. 5, No. 4, 2004, p. 271.

[10] Dorofee A.J., Walker J.A., Alberts C.J., Higuera R.P., Murphy R.L., Williams R.C., Continuous risks management guidebook, Software Engineering Institute (SEI), 1996, Pittsburgh, EEUU.

[11] Saaty T.L., The Analytic Hierarchy Process: Planning, Priority Setting, Resource Allocation, McGrawHill, 1980, New York, EEUU.
[12] Saaty T.L., A scaling method for priorities in hierarchical structures, Journal of Mathematical Psychology, Vol. 15, No. 3, 1977, pp. 234-281.

[13] Zahedi F., The analytic hierarchy process. A survey of the method and its applications, Interfaces, Vol. 16, No. 4, 1986, pp. 96-108.

[14] Okoli, C., Pawlowski S., The Delphi method as a research tool: an example, design considerations and applications, Information \& Management, Vol. 42, No. 1, 2004, pp. 15-29.

[15] Clayton, M., Delphi: a technique to harness expert opinion for critical decision-making tasks in education, Educational Psychology, Dorchesteron - Thames, Vol. 17, No. 4, 1997, pp. 373-387.

\section{Acknowledgments}

The authors wish to thank the Spanish Ministry of Science and Technology (MICINN-ECO2009.12853) and the Andalusian Regional Government (CICE-P07-SEJ03080) for their financial support 


\section{Authors' Biographies}

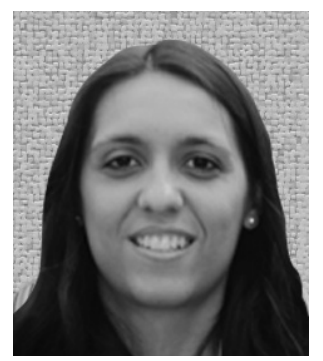

\section{Cristina LÓPEZ}

She is an assistant professor at the School of Engineering at Universidad Pablo of Olavide. At present, she participates in various research projects at a national level. Her papers have been published in Journal of Systems and Software, IEEE Transactions on Software Engineering, among others. Her research interests include enterprise systems and project risk management. She is an active participant in conferences in these areas.

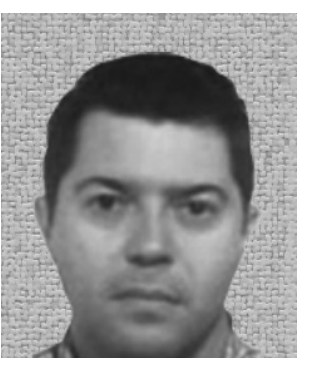

\section{Jose LUIS SALMERÓN}

$\mathrm{He}$ is a professor at the School of Engineering at Universidad Pablo of Olavide. Dr. Salmeron has co-authored eight books and has served as a visiting scholar and researcher at Texas Tech University and at several Spanish universities. At present, he is leading research projects at a national and international level. His papers have been published in IEEE Transactions on Software Engineering, Expert Systems with Applications, International Journal of Approximate Reasoning, Communications of the ACM, Journal of Systems and Software, Knowledge-Based Systems, Computer Standards \& Interfaces, Information \& Management, Interacting with Computers, Technovation, Industrial Management \& Data Systems, European Journal of Operational Research, Scientometrics, among others. He is actively conducting research in fuzzy cognitive maps, computational intelligence, and complex adaptive systems. 